\title{
Enhanced Penetration Depth during Reduced Pressure Keyhole-Mode Laser Welding
}

\author{
Modeling and experiments took place to understand \\ deeper laser keyholes at lower pressures
}

BY M. JIANG, Y. B. CHEN, X. CHEN, W. TAO, AND T. DEBROY

\begin{abstract}
Keyhole-mode laser welding under reduced ambient pressure is known to provide improved weld penetration, narrower width, and reduced incidences of defects, but the underlying mechanism for these benefits is not known. We sought to elucidate the mechanism by an experimental and theoretical program of investigation. Potential causative factors, such as the depression of the boiling point of alloys at reduced pressures and the changes in laser beam attenuation by metal vapors/plasma, were investigated using a well-tested heat transfer and fluid flow model of keyhole-mode laser welding for various ambient pressures. The model was tested with experimental data for the welding of four alloys - Structural Steel Q690, Aluminum Alloy A5083, commercially pure titanium, and Nickel 201 - that have very different thermophysical properties. The results showed the changes in the boiling point alone were unable to explain the enhanced depth of penetration at low ambient pressures. The experimental and calculated fusion zone geometries showed excellent agreement when both the boiling point depression and the beam attenuation by metal vapor were considered. The reduction of ambient pressure also affected the heat transfer pattern near the keyhole, owing to a decrease in the keyhole wall temperature and changes in the temperature gradient near the keyhole wall.
\end{abstract}

\section{KEYWORDS}

- Laser Welding • Ambient Pressure • Keyhole Depth

- Heat Transfer • Fluid Flow • Weld Geometry

- Boiling Point • Beam Attenuation

\section{Introduction}

High energy density welding, such as laser or electron beam welding, is often used for the fabrication of thick section components where a high aspect ratio (depth/width) and a narrow heat-affected zone (HAZ) are desired. Laser welding, commonly used at atmospheric pressure, underperforms electron beam welding, conducted at much lower pressures, in both depth of penetration of welds and reduced incidences of defects such as macroporosity (Refs. 13). With the development of ultra-high power lasers, 10- to 100-kW lasers have now became available for welding (Refs.
4-6). They enable welding with improved depth of penetration, but weld defects are easily formed when higher depth of penetration is achieved by increasing laser power (Refs. 7-9). Process parameter optimization (Refs. 10, 11), shielding gas adjustment (Refs. 12), laser beam modulation (Refs. $13,14)$, addition of an external energy field (Ref. 15), and application of vacuum (Refs. 16, 17) were attempted to improve weld quality in high-power laser welding. These previous works have shown that reducing ambient pressure in laser welding is the most effective method for improving both the penetration depth and weld quality.

Laser welding under vacuum or reduced ambient pressure was first reported by Arata et al. in the 1980s (Ref. 18). After that, several studies have confirmed a reduction of the ambient pressure had a significant beneficial effect on weld geometry and defects (Refs. 19-24). For example, Katayama et al. showed, for certain welding conditions, the depth of penetration under vacuum was about twice that obtained at atmospheric pressure for the same welding parameters (Ref. 19). A laser weld with narrow and deep fusion zone geometry characteristics of electron beam welds could be obtained at reduced ambient pressures between $10^{-3}$ and $10^{-2}$ atmosphere (atm) (Ref. 17), which is much higher than the typical operating pressure $\left(10^{-7} \mathrm{~atm}\right)$ of electron beam welding. An operating vacuum of about $10^{-3} \mathrm{~atm}$ is very easy to achieve quickly using a simple mechanical pump. The excellent weld quality and less stringent vacuum requirement make laser welding at a reduced pressure compete favorably with electron beam welding.

The important roles of the reduction of boiling point and the interaction of laser and plasma plume owing to a reduction of ambient pressure have been recognized in the literature. The commonly observed plasma plume at atmospheric pressure practically disappeared when ambient pressure was reduced (Ref. 20). Youhei et al. (Ref. 25) studied the effect of ambient pressure on the attenuation of a low-power solid state laser beam passed horizontally through a plasma/ vapor plume. They showed the effect of plasma plume was significantly diminished as the ambient pressure was reduced. Similarly, Jiang et al. (Ref. 26) also demonstrated the laser energy attenuation caused by the plasma plume significantly decreased with a decreasing ambient pressure. The boiling point of alloys is also significantly affected by the ambient pressure. Reisgen et al. (Ref. 17) suggested the smaller difference between the boiling point and the melting point under vacuum would result in a thinner molten pool. 
Various mathematical models ranging from heat conduction simulations to comprehensive 3D heat transfer and fluid flow calculations, considering the presence of a moving liquidvapor interface for keyhole-mode laser welding and electron beam welding, are available in the literature (Refs. 27-38). However, most of previous models did not consider the effect of ambient pressure. A quantitative study is needed to definitively elucidate the mechanism by which the benefits of reduced ambient pressure keyhole-mode laser welding are achieved. Numerical simulation of heat transfer, considering both the depression of the boiling point and the attenuation of the laser beam by metal vapor/plasma, can provide a realistic assessment of the development of the fusion zone geometry during keyhole-mode welding of alloys at various pressures.

Here, we sought to elucidate the underlying mechanism for the enhanced depth of penetration during keyhole-mode laser welding at reduced ambient pressure through experiments and modeling. We developed a 3D heat transfer and fluid flow model for the keyhole-mode welding at various ambient pressures. The model considers the role of ambient pressure by including its effects on the depression of the boiling point of the alloy and the variation of plume attenuation coefficient. The predictions of the model were tested with experimental data for the keyhole-mode welding of four alloys - Structural Steel Q690, Aluminum Alloy A5083, commercially pure titanium, and Nickel 201 (Ref. 16) - that have very different thermophysical properties. Both the depression of the boiling point and the pressure dependent variation of the metal vapor/plasma plume attenuation of the beam intensity are shown to be responsible for the superior performance of the keyhole-mode laser beam welding at reduced ambient pressure. Analysis of the results also show the local heat transfer patterns near the keyhole changes with ambient pressure and contributes to the fusion zone shape and size.

\section{Experimental Procedure}

Laser welds under reduced ambient pressures were made in a specially designed vacuum chamber. Figure 1 shows a schematic diagram of the experimental setup. An IPG continuous wavelength fiber laser with maximum output of $10 \mathrm{~kW}$ was used in this experiment. The 1070-nm wavelength laser was transmitted via a $200-\mu$ m-diameter optical fiber to a laser head equipped with a set of 1:2.3 focusing optics, consisting of 200-mm collimator lens and 460-mm focus lens. Therefore, the beam at focus had a theoretical spot size of approximately $0.46 \mathrm{~mm}$. The vacuum chamber contained a mobile platform on which the specimen was welded. A two-stage pumping system consisting of a $15-\mathrm{L} / \mathrm{s}$ rotary pump and a $70-\mathrm{L} / \mathrm{s}$ roots pump was used to rapidly attain the preset ambient pressure.

Bead-on-plate laser beam welding was performed on 15mm-thick Structural Steel Q690 and Aluminum Alloy A5083 samples at a laser power of $5000 \mathrm{~W}$ and a welding speed of $16.7 \mathrm{~mm} / \mathrm{s}$. The laser beam was focused on the specimen surface, i.e., no defocusing was used. Structural Steel Q690 had a composition of $1.28 \% \mathrm{Mn}, 0.26 \% \mathrm{Si}, 0.19 \% \mathrm{Cr}, 0.16 \%$ C, $0.13 \% \mathrm{Mo}, 0.027 \% \mathrm{Nb}, 0.02 \% \mathrm{Ni}, 0.018 \% \mathrm{Ti}, 0.007 \% \mathrm{P}$, $0.003 \%$ P, and balance Fe. The Aluminum Alloy A5083 had a composition of $0.1 \% \mathrm{Cu}, 0.4 \% \mathrm{Si}, 0.4 \% \mathrm{Fe}, 4.1 \% \mathrm{Mg}, 0.08 \%$ $\mathrm{Cr}, 0.25 \% \mathrm{Zn}, 0.15 \% \mathrm{Ti}$, and balance Al. After laser welding, the specimens were prepared for metallography using a wire electrical discharge machining. The samples were polished and etched according to standard procedure, and the fusion zone cross sections were obtained using a digital optical microscope. The data for the Grade 2 commercially pure titanium (> $99.5 \mathrm{wt}-\% \mathrm{Ti}$ ) and Nickel 201 (> $99 \mathrm{wt}-\% \mathrm{Ni}$ ) were taken from literature (Ref. 16).

\section{Mathematical Model}

A three-dimensional heat transfer and fluid flow model for laser welding under reduced ambient pressure was developed by modifying our previous keyhole-mode welding models (Refs. 39-44). The model considers the main physical process during keyhole-mode laser welding, including keyhole formation, liquid metal flow driven by the spatial gradient of surface tension, melting, solidification, two-phase mushy zone, and heat transfer in the weldment. The quasi-steady state assumption makes the model computationally efficient. Details about this model are available in the literature (Refs. 39-44), and only the salient features of the model are presented here. The data used for calculation are presented in Table 1.

\section{Keyhole Calculation}

A point-by-point heat balance and pressure balance on the keyhole wall was used to calculate the keyhole geometry in this model. The calculation of keyhole geometry was based on materials properties and welding parameters. The calculation procedure includes the following steps.

An initial keyhole geometry was determined by a pointby-point energy balance on the keyhole wall. The detailed procedures of the point-by-point energy balance are provided in Appendix A. The keyhole wall temperature was assumed as the boiling point at the local pressure, which was determined by the equilibrium pressure vs. the temperature relationship for the base metal. The multiple reflections of the

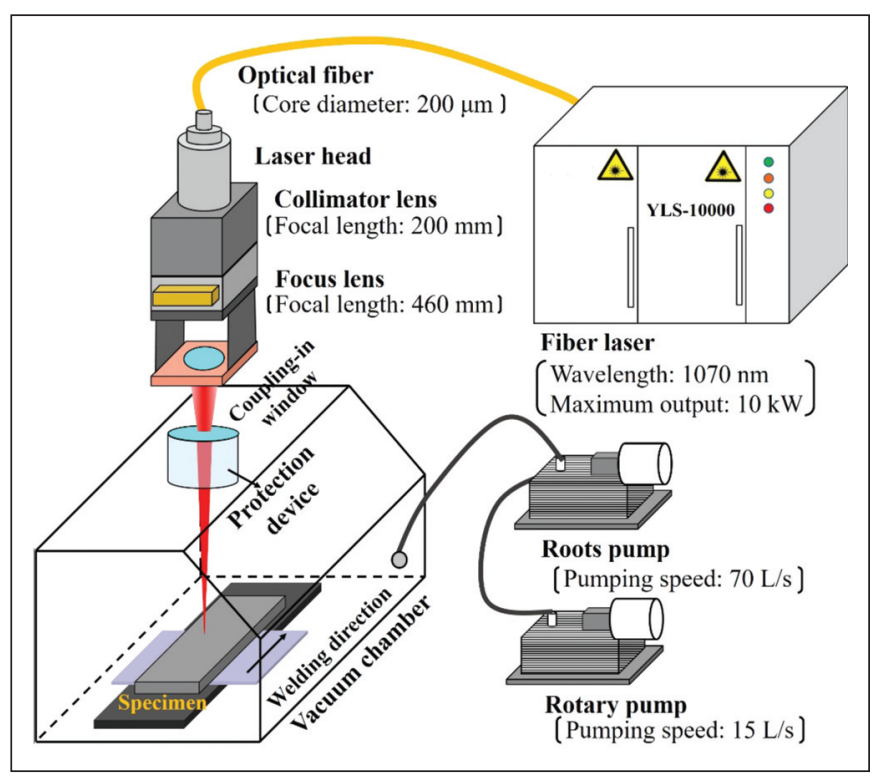

Fig. 1-A schematic diagram of the experimental setup used for laser welding under reduced ambient pressure. 


\begin{tabular}{|c|c|c|c|c|}
\hline Physical Property & $\begin{array}{c}\text { Structural } \\
\text { Steel (Q690) }\end{array}$ & $\begin{array}{l}\text { Aluminum } \\
\text { Alloy (5083) }\end{array}$ & $\begin{array}{c}\text { Titanium } \\
\text { (commercial purity) }\end{array}$ & $\begin{array}{l}\text { Nickel } \\
(201)\end{array}$ \\
\hline Density at the boiling point $\left(\mathrm{kg} \mathrm{m}^{-3}\right)$ & 5800 & 2380 & 4110 & 7800 \\
\hline Heat of evaporation $\left(\mathrm{J} \mathrm{kg}^{-1}\right)$ & $6.52 \times 10^{6}(\mathrm{Fe})$ & $\begin{array}{c}1.05 \times 10^{7}(\mathrm{Al}) \\
5.26 \times 10^{6}(\mathrm{Mg})\end{array}$ & $1.03 \times 10^{6}(\mathrm{Ti})$ & $\begin{array}{l}6.21 \times 10^{6} \\
(\mathrm{Ni})\end{array}$ \\
\hline Heat of fusion $\left(\mathrm{J} \mathrm{kg}^{-1}\right)$ & $1.2 \times 10^{5}$ & $3.95 \times 10^{5}$ & $2.9 \times 10^{5}$ & $3.0 \times 10^{5}$ \\
\hline Solidus temperature $(\mathrm{K})$ & 1745 & 847 & 1941 & 1708 \\
\hline Liquidus temperature $(\mathrm{K})$ & 1785 & 933 & 1941 & 1719 \\
\hline Viscosity $\left(\mathrm{kg} \mathrm{m}^{-1} \mathrm{~s}^{-1}\right)$ & $6.7 \times 10^{-3}$ & $4.2 \times 10^{-3}$ & $5.0 \times 10^{-3}$ & $5.31 \times 10^{-3}$ \\
\hline Specific heat of liquid $\left(\mathrm{Jg}^{-1} \mathrm{~K}^{-1}\right)$ & 795 & 1197 & 800 & 500 \\
\hline 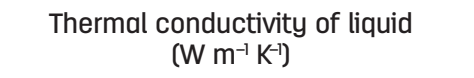 & 21 & 90 & 28 & 74.9 \\
\hline 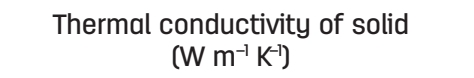 & 21 & 235 & 28 & 74.9 \\
\hline Coefficient of thermal expansion $\left(\mathrm{K}^{-1}\right)$ & $1.0 \times 10^{-5}$ & $1.0 \times 10^{-6}$ & $1.5 \times 10^{-4}$ & $1.33 \times 10^{-5}$ \\
\hline$d \gamma / d T$ of material $\left(\mathrm{N} \mathrm{m}^{-1} \mathrm{~K}^{-1}\right)$ & $-0.49 \times 10^{-3}$ & $-0.15 \times 10^{-3}$ & $-0.26 \times 10^{-3}$ & $-0.37 \times 10^{-3}$ \\
\hline Surface tension $\left(\mathrm{N} \mathrm{m}^{-1}\right)$ & 1.87 & 1.67 & 1.7 & 1.82 \\
\hline $\begin{array}{l}\text { Plume attenuation coefficient } \\
\text { at atmospheric pressure }\left(\mathrm{cm}^{-1}\right)\end{array}$ & 3 & 4 & 5 & 3.5 \\
\hline
\end{tabular}

laser beam inside the keyhole was considered by calculating the number of reflections according to the keyhole geometry. The beam attenuation was computed by using a plume attenuation coefficient in the model. The initial keyhole geometry was refreshed according to the energy absorption induced by multiple reflections and the energy attenuation caused by metal vapor/plasma. After the calculation of the initial keyhole geometry, the keyhole geometry data was stored in a data file to do the following calculations.

Secondly, the keyhole wall temperatures were modified according to the pressure balance on the keyhole wall. Inside the keyhole, the vapor pressure tended to keep the vapor cavity open, while the surface tension and hydrostatic pressure tried to close the keyhole. The force balance on the keyhole wall was given as follows:

$$
P_{v}=P_{A}+\gamma(T) / r(z)+\rho g z
$$

where $P_{v}$ is the vapor pressure inside the keyhole, $P_{A}$ is the ambient pressure, $\gamma(T)$ is the surface tension at local wall temperature $T, \rho$ is the density, and $g$ is the acceleration due to gravity. $r(z)$ is the average keyhole radius at the depth $z$ from the top surface and is taken as half of the keyhole diameter in the welding direction. The vapor pressure at any depth $\mathrm{z}$ from the top surface is calculated using Equation 1 according to the saved data of keyhole geometry in the first step. Subsequently, the temperature on the keyhole wall at any depth can be calculated from the equilibrium temperature vs. pressure relation, assuming ideal solution behavior.

Thirdly, the point-by-point energy balance was conducted again using the modified value of keyhole wall temperatures at all depths. Finally, the pressure and energy balance were done alternately and repeatedly to correct the keyhole geometry and keyhole wall temperature. The iterations were stopped when the keyhole depth became less than $10^{-4} \mathrm{~mm}$.

\section{Heat Transfer and Fluid Flow in the Weld Pool}

After the calculation of keyhole geometry, the computed keyhole profile was mapped into a calculation domain for subsequent calculation of fluid flow and heat transfer. The molten metal was assumed to be an incompressible, laminar, and Newtonian fluid. The 3D fluid flow and temperature field were determined by solving the following conservation equations of momentum, mass, and energy.

\section{Momentum Conservation Equation or Navier-Stokes Equation (Refs. 41, 45)}

$$
\rho \frac{\partial u_{j}}{\partial t}+\rho \frac{\partial\left(u_{i} u_{j}\right)}{\partial x_{i}}=\frac{\partial}{\partial x_{i}}\left(\mu \frac{\partial u_{j}}{\partial x_{i}}\right)+S_{j}
$$

where $\rho$ and $\mu$ are the density and the viscosity of the alloy, 
respectively; $u_{i}$ and $u_{j}$ are the velocity components along the $i$ and $j$ directions, respectively; and $S_{j}$ is the source term for the momentum conservation equation and is given as follows:

$$
\begin{aligned}
& S_{j}=-\frac{\partial p}{\partial x_{j}}+\frac{\partial}{\partial x_{j}}\left(\mu \frac{\partial u_{j}}{\partial x_{j}}\right)-C\left(\frac{\left(1-f_{L}\right)^{2}}{f_{L}^{3}+B}\right) u_{j} \\
& +\rho g \beta\left(T-T_{r e f}\right)-\rho U \frac{\partial u_{j}}{\partial x_{j}}
\end{aligned}
$$

where $p$ represents pressure, $U$ is the welding velocity, and $\beta$ is the coefficient of volume expansion. The third term represents the frictional dissipation in the mushy zone according to the Carman-Kozeny equation for flow through a porous media (Refs. 32,46 ), where $f_{L}$ is the liquid fraction, $B$ is a very small computational constant introduced to avoid division by zero, and $C$ is a constant accounting for the mushy zone morphology. The fourth term is the buoyancy source term. The last term accounts for the relative motion between the laser source and the workpiece (Refs. 47, 48).

\section{Mass Conservation Equation or Continuity Equation}

$$
\frac{\partial\left(\rho u_{i}\right)}{\partial x_{i}}=0
$$

The mass conservation equation is solved in conjunction with the momentum equation to obtain the pressure field.

\section{Energy Equation}

$$
\rho \frac{\partial h}{\partial t}+\rho \frac{\partial\left(u_{i} h\right)}{\partial x_{i}}=\frac{\partial}{\partial x_{i}}\left(\frac{k}{c_{p}} \frac{\partial h}{\partial x_{i}}\right)+S_{h}
$$

where $k$ is the thermal conductivity and $h$ is the sensible heat. The sensible heat $h$ is expressed as follows: $h=\int C_{p} d T$, where $C_{p}$ is the specific heat and $T$ is the temperature. The source term $S_{h}$ is due to the latent heat content and is given as follows:

$$
S_{h}=-\rho \frac{\partial(\Delta H)}{\partial t}-\rho \frac{\partial\left(u_{i} \Delta H\right)}{\partial x_{i}}-\rho U \frac{\partial h}{\partial x_{i}}-\rho U \frac{\partial \Delta H}{\partial x_{i}}
$$

where $\Delta H$ is the latent heat content. The latent heat content $\Delta H$ is given as follows: $\Delta H=f_{L} L$, where $L$ is the latent heat of fusion. The liquid fraction $f_{L}$ is assumed to vary linearly with temperature for simplicity (Ref. 47), and is given as follows:

$$
f_{L}=\left\{\begin{array}{cc}
1 & T \geq T_{L} \\
\frac{T-T_{S}}{T_{L}-T_{S}} & T_{S}<T<T_{L} \\
0 & T \leq T_{S}
\end{array}\right.
$$

where $T_{L}$ and $T_{S}$ are the liquidus and solidus temperatures, respectively.

The heat transfer and fluid flow equations were solved in three dimensions for the complete workpiece. For the region inside the keyhole, the coefficients and source terms in the discretized algebraic equations were adjusted to obtain the modified keyhole wall temperature at all depths and zero fluid velocities.

\section{Boundary Conditions}

A 3D Cartesian coordinate system was used in the calculation, and only half of the workpiece was considered because of the symmetry of welding process with respect to the weld centerline. A schematic of the boundary conditions is shown in Fig. 2. These boundary conditions are further discussed as follows.

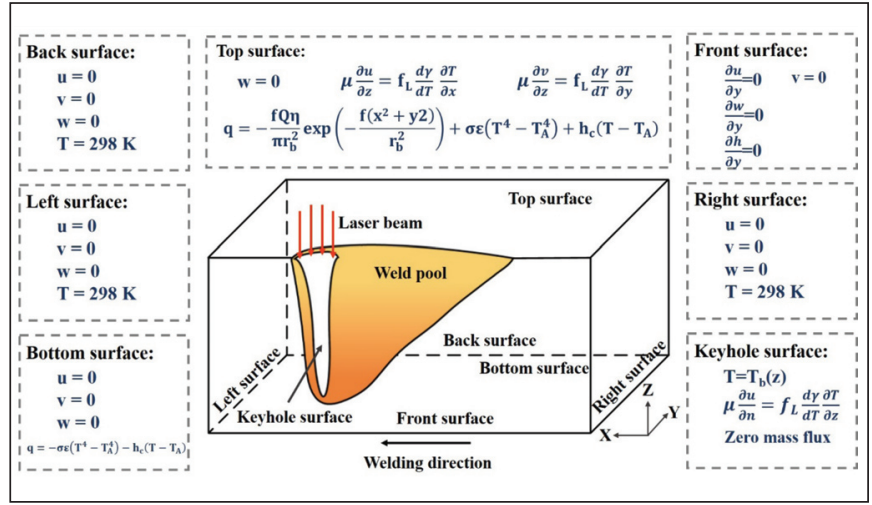

Fig. 2 - Schematic diagram of boundary conditions.

\section{Top Surface}

The top surface, except the keyhole region, is assumed to be flat. The velocity components along the $\mathrm{x}$ and $\mathrm{y}$ direction, $u$ and $v$, induced by the Marangoni effect were considered as the velocity boundary condition (Ref. 49). The velocity components along the $\mathrm{z}$ direction, $w$, is set as zero due to the negligible outward flow at the top surface. Therefore, the

$$
\left\{\begin{array}{c}
\mu \frac{\partial u}{\partial z}=f_{L} \frac{\partial \gamma}{\partial T} \frac{\partial T}{\partial x} \\
\mu \frac{\partial v}{\partial z}=f_{L} \frac{\partial \gamma}{\partial T} \frac{\partial T}{\partial y} \\
w=0
\end{array}\right.
$$

where the $d \gamma / d T$ is the temperature coefficient of surface tension.

The heat boundary condition was derived from the heat input and heat loss by radiation and convection. The expression is given as follows: 
$q=-\frac{f Q \eta}{\pi r_{b}^{2}} \exp \left(-\frac{f(x 2+y 2)}{r_{b}^{2}}\right)+\sigma \varepsilon\left(T^{4}-T_{A}^{4}\right)+h_{c}\left(T-T_{A}\right)$

where $r_{b}$ is the beam radius, $f$ is the power distribution factor, $Q$ is the total power, $\eta$ is the absorption coefficient, $\sigma$ is the Stefan-Boltzmann constant, $\varepsilon$ is the emissivity, $h_{c}$ is the heat transfer coefficient, and $T_{A}$ is the ambient temperature. In Equation 9, the first term on the right-hand side is the heat input from the heat source. The second and third terms represent the heat loss by radiation and convection, respectively.

\section{Symmetry Plane}

The symmetric plane is the front surface in Fig. 2. Zero flux condition was applied for both momentum and enthalpy at the symmetric plane. Therefore, the velocity components and heat flux along the y direction were set as zero. The boundary condition can be defined as follows:

$$
\left\{\begin{array}{l}
\frac{\partial u}{\partial y}=0 \\
v=0 \\
\frac{\partial w}{\partial y}=0 \\
\frac{\partial h}{\partial y}=0
\end{array}\right.
$$

\section{Keyhole Surface}

The keyhole wall temperature at any depth was fixed by assigning a corresponding enthalpy value at that depth:

$$
h=h_{b}(z)
$$

where $h_{b}(z)$ is the sensible heat of the material at the local wall temperature, which is determined by the wall temperature at depth $\mathrm{z}$ from the keyhole geometry calculation. The velocity component perpendicular to the keyhole surface was assigned zero to represent no mass flux due to convection. The temperature gradient along the keyhole wall resulted in the melt flow along the $z$ direction. Therefore, the $w$ velocity boundary condition along the keyhole walls is given as follows:

$$
\mu \frac{\partial u}{\partial n}=f_{L} \frac{\partial \gamma}{d T} \frac{\partial T}{\partial z}
$$

where $n$ is the direction vector normal to the keyhole surface.

\section{Bottom Surface}

Fluid velocities at three directions were fixed at zero because of the no-melt flow on the bottom surface in partial joint penetration welds. A radiation and convective heat transfer boundary condition with a given heat transfer coefficient was specified for the bottom surface.

\section{Solid Surfaces}

At all the solid surfaces far away from the weld pool, including the back, left, and right surfaces in Fig. 2, temperatures were set at ambient temperature, and the fluid velocities were set to be zero.

\section{Turbulence Model}

During keyhole-mode laser welding, the presence of fluctuating velocities in the weld pool often enhances the transport rates of heat, mass, and momentum. The values of effective viscosity and thermal conductivity vary with the location in the weld pool and depend on the local characteristics of the fluid flow. An appropriate turbulence model is needed to provide a systematic framework for calculating these properties by considering the contribution of the fluctuating velocities. In this work, a turbulence model based on Prandtl's mixing length hypothesis was used to estimate the turbulent viscosity (Ref. 41):

$$
\mu_{t}=\rho l_{m} v_{t}
$$

where $\mu_{t}$ is the turbulent viscosity, $l_{m}$ is the mixing length, and $v_{t}$ is the turbulence velocity. The turbulence velocity can be estimated from the turbulent kinetic energy. The turbulent kinetic energy (TKE) is assumed to be about $10 \%$ of the mean kinetic energy. It follows that TKE $\left(0.5 \mathrm{mv}_{\mathrm{t}}^{2}\right)$ equals $0.1 \times 0.5 \mathrm{mv}^{2}$ and the fluctuating component of the mean velocity, $\mathrm{v}_{\mathrm{t}}$, becomes equal to $0.316 \mathrm{v}$. Thus, the turbulent component of the velocity (or fluctuating velocity) is about $30 \%$ of the mean velocity, and the turbulent viscosity can be expressed by the following expression:

$$
\mu_{t}=0.3 \rho l_{m} v
$$

Effective viscosity at a particular point was given as the sum of the turbulent $\left(u_{t}\right)$ and laminar $\left(u_{l}\right)$ viscosities, i.e., $u=u_{t}+u_{l}$. The corresponding local turbulent thermal conductivity $k_{t}$ was calculated from the turbulent Prandtl number

$$
\operatorname{Pr}=u_{t} c_{p} / k_{t}
$$

For the calculations described here, the Prandtl number was set to a value of 0.9 , based on previous modeling work (Ref. 49).

\section{Results and Discussion}

Figure 3 shows a comparison between the calculated and the experimentally observed fusion zone cross sections for the keyhole-mode welding of Structural Steel Q690. The red line indicates the solidus temperature (1745 K), which marks the weld fusion cross-section boundary. The black line in the figure indicates the $\mathrm{A} 1$ line temperature $(1000 \mathrm{~K})$, which marks the HAZ region of the weld section. The experimental results showed the weld depth and half weld width were 4.23 and $1.6 \mathrm{~mm}$, respectively, and the corresponding computed values were 4.43 and $1.55 \mathrm{~mm}$, respectively. The calculated weld fusion cross section and HAZ agreed well with the corresponding experimental results. 


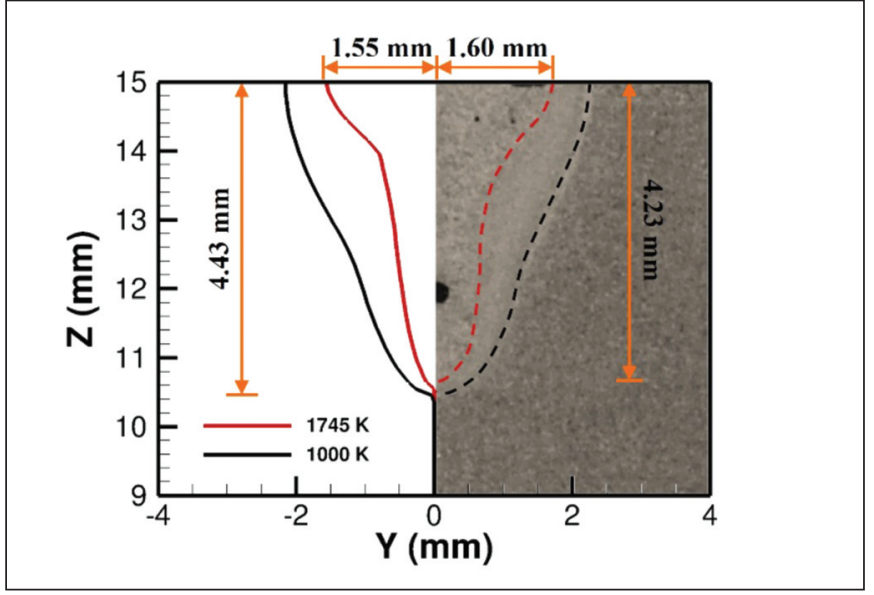

Fig. 3 - Comparison between the calculated weld fusion cross sections and HAZs of the laser weld for Structural Steel Q690 obtained at atmospheric pressure with the corresponding experimental results.

Boiling point is the temperature at which the equilibrium vapor pressure of a liquid alloy equals the ambient pressure surrounding the liquid. Therefore, ambient pressure has a significant effect on boiling point. In our model, the equilibrium vapor pressure was calculated, assuming ideal solution behavior according to the alloy composition. In this study, the relationship of temperature and the equilibrium vapor pressure over the pure-iron liquid was used for Structural Steel Q690 because the iron content is more than $98 \%$ in the base metal. The equation of equilibrium vapor pressure of pure iron vs. temperature is given by Yaws (Ref. 50).

$$
\begin{aligned}
& \log (P \times 760)=11.559-\frac{1.9538}{T}-0.62549 \log T \\
& -2.7182 \times 10^{-9} \mathrm{~T}+1.9086 \times 10^{-13} \mathrm{~T}^{2}
\end{aligned}
$$

where $P$ is the equilibrium vapor pressure, and $T$ is the temperature.

Figure 4 shows the calculated boiling point of Structural Steel Q690 at different ambient pressures according to Equation 13. The boiling point decreased dramatically with the decrease in ambient pressure. The difference in boiling point for pure iron is about $1000 \mathrm{~K}$ when the ambient pressure ranged from 1 to 0.001 atm.

The effect of ambient pressure on boiling point was considered in the heat transfer and fluid flow model. In the calculation of keyhole geometry, the boiling point at any local ambient pressure was considered as the local keyhole wall temperature according to the boiling point vs. ambient pressure relationship in Equation 13.

Figure 5 shows the experimental and the corresponding calculated penetration depth and weld width for Structural Steel Q690 by only considering the variation of boiling point for five ambient pressures. In Fig. 5A, the experimental results show the penetration depth increased significantly from 4.23 to $10.21 \mathrm{~mm}$ with the decrease of ambient pressure from 1 to $0.01 \mathrm{~atm}$, but when the ambient pressure reduced to $0.01 \mathrm{~atm}$ and below, the penetration depth re-

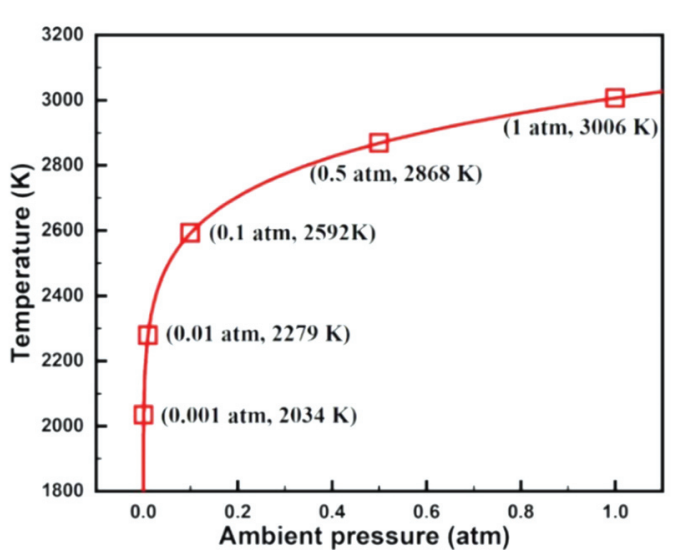

Fig. 4 - The calculated boiling point of Structural Steel Q690 at different ambient pressures according to the equation of equilibrium vapor pressure vs. temperature given by Yaws (Ref. 50).

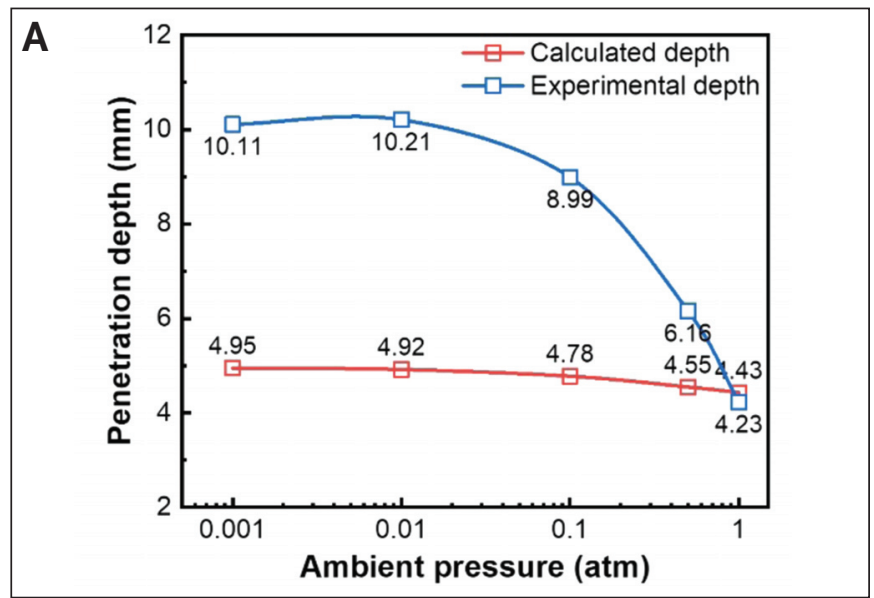

B

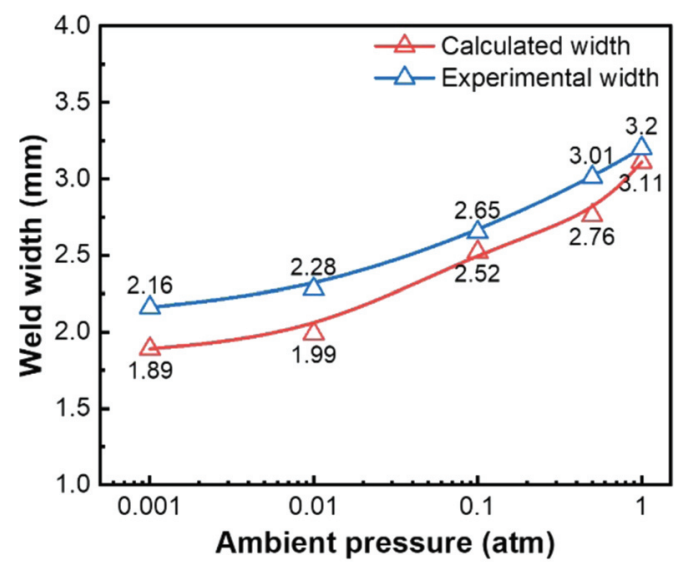

Fig. 5 - The experimental and corresponding calculations: A - Penetration depth; B - weld width for Structural Steel Q690 by only considering the variation in boiling point for five ambient pressures. 

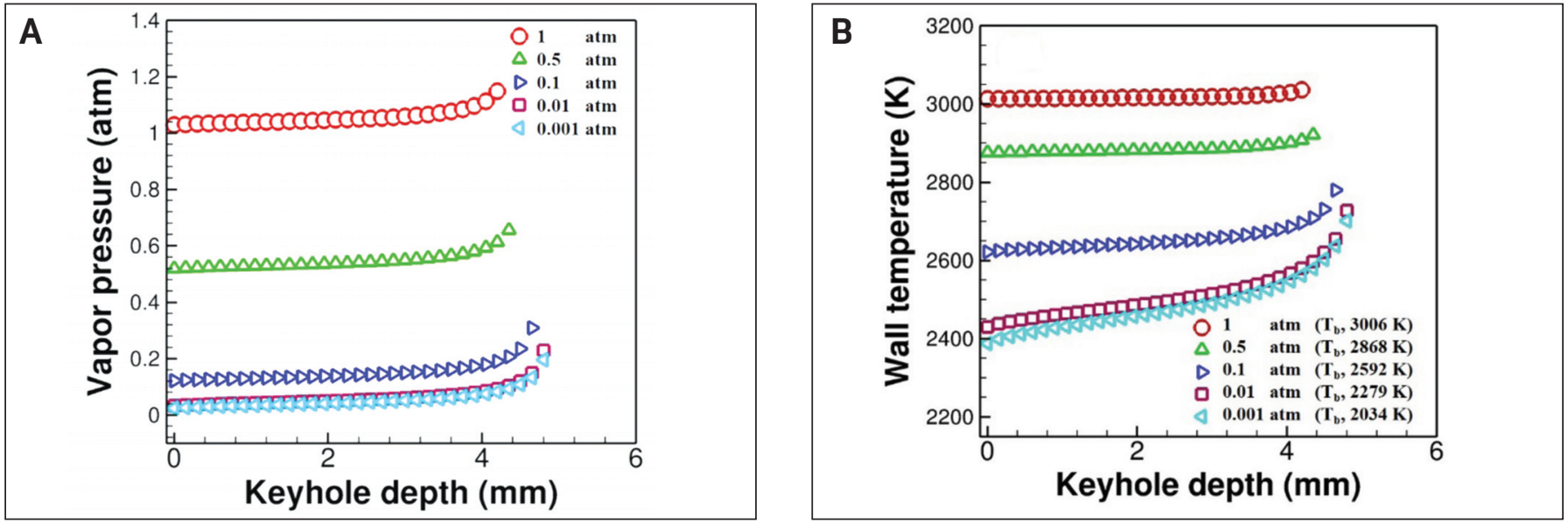

Fig. 6 - The variation of the following: A - Vapor pressure; B - keyhole wall temperature with keyhole depth for laser welding of Structural Steel $\mathrm{Q} 690$ at five level ambient pressures by only considering the variation in boiling point. ( $T_{b}$ indicates the boiling temperature in Fig. 6B.)

mained stable. The calculated results show the reduction of boiling point only induced an increase of $0.5 \mathrm{~mm}$ in penetration depth when the ambient pressure ranged from 1 to 0.001 atm. In contrast, as shown in Fig. 5B, the calculated weld width had a good agreement with the corresponding experimental results. Both the experimental and calculated weld width decreased from about 3 to about $2 \mathrm{~mm}$ when ambient pressure was reduced from 1 to $0.001 \mathrm{~atm}$.

Figure 6A shows the variation of vapor pressure with keyhole depth for laser welding of Structural Steel Q690 with 5-kW input power and $16.7-\mathrm{mm} / \mathrm{s}$ welding speed for five values of ambient pressures. The values in the plot conformed to the pressure balance, considering the surface ten- sion and hydrostatic pressures at the keyhole wall. A pressure difference between the bottom and the top of keyhole exited to keep the keyhole open. Therefore, the vapor pressure was greater than 1 atm for welding at atmospheric pressure. The results show that although the vapor pressure values depended on the ambient pressure, the difference in pressure from the bottom to the top of the keyhole for different ambient pressures were roughly similar. Figure $6 \mathrm{~B}$ shows the variation of the calculated keyhole wall temperature with keyhole depth for various ambient pressures. As expected, the keyhole wall temperature decreased with the decrease in boiling point. Furthermore, owing to the similar vapor pressures inside the keyhole, the keyhole wall temper-

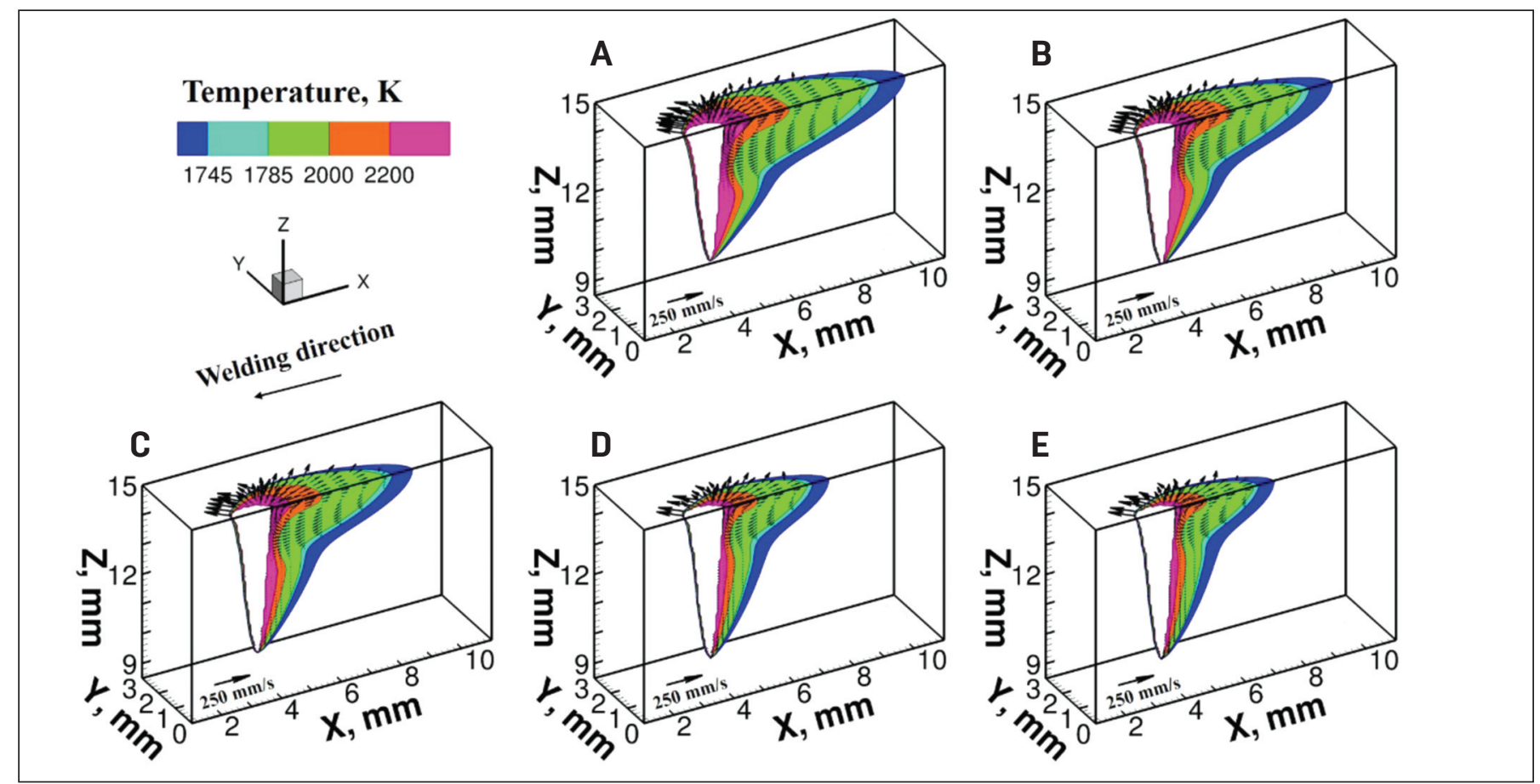

Fig. 7 - The calculated temperature and fluid flow field for laser welding of Structural Steel Q690 at five level ambient pressures: $A-1 \mathrm{~atm} ; \mathrm{B}-0.5 \mathrm{~atm} ; C-0.1 \mathrm{~atm} ; D-0.01 \mathrm{~atm} ; E-0.001 \mathrm{~atm}$ by only considering the variation in boiling point. 
atures were similar for ambient pressures of 0.01 and 0.001 atm. More important, the temperature gradient along the keyhole wall was different for various ambient pressures. Although an excess pressure inside the keyhole from the bottom to the top exited at atmospheric pressure, the temperature gradient on the keyhole wall was very small at an ambient pressure of $1 \mathrm{~atm}$. This is the reason why the keyhole wall temperature can be set as boiling in the simulation of conventional laser welding at atmospheric pressure (1 atm) (Refs. 33, 39). For a similar excess pressure in the keyhole at reduced ambient pressure, the temperature difference between the bottom and the top of the keyhole was much larger than the corresponding value for laser welding at atmospheric pressure. The wall temperature varied by about $313 \mathrm{~K}$ from the $2388 \mathrm{~K}$ at the top surface to $2701 \mathrm{~K}$ near the keyhole bottom at an ambient pressure of 0.001 atm. The temperature gradient on the keyhole wall drove a Marangoni convection along the keyhole wall.

Figure 7 shows the calculated temperature and fluid flow field during laser welding of Structural Steel Q690 at $5 \mathrm{~kW}$ and $16.7 \mathrm{~mm} / \mathrm{s}$ for various ambient pressures by only considering the variation in boiling point. The lower keyhole wall temperature reduced heat conduction in the horizontal direction at a reduced ambient pressure compared with the atmospheric pressure. Therefore, the weld pool length and weld pool width decreased with the decrease in ambient pressure. There was no significant Marangoni convection along the keyhole walls at atmospheric pressure because of the lack of a strong temperature gradient along the keyhole wall. While at reduced ambient pressure, there was an upward flow on the keyhole walls due to the Marangoni convection. It drove the melt liquid to flow from the hightemperature region to the low-temperature region and brought heat from the keyhole bottom to the surface. Although the decrease in boiling point was not the main reason for the improvement of penetration depth in laser welding under reduced ambient pressure, it significantly changed the heat transfer and fluid flow in the weld pool.

When a high-power density laser impinges on a base metal surface, the material vaporizes violently, resulting in the formation of a deep and narrow cavity called keyhole (Refs. $35,42)$. A plasma/vapor plume forms during welding and consists of ions, excited atoms, neutral atoms, and electrons (Refs. 51-53). The number densities of each species depend on the vaporization rates of various alloying elements, laser beam power density distribution, shielding gas flow rate, and total pressure (Refs. 54-58). Figure 8A shows, schematically, as the laser beam traverses through the plasma plume into the keyhole, the laser energy decreases due to the attenuation by vapor/plasma plume before it is absorbed by the keyhole wall. An important component of the attenuation is through the inverse Bremsstrahlung absorption, which involves electron-atom and electron-ion collisions. It has been demonstrated the inverse Bremsstrahlung absorption is the main absorption mechanism for a $\mathrm{CO}_{2}$ laser (wavelength: $10.6 \mu \mathrm{m}$ ) (Refs. 56-58). While for solidstate laser with a wavelength of about $1 \mu \mathrm{m}$, the inverse Bremsstrahlung absorption can be negligible because the inverse Bremsstrahlung absorption is directly proportional to the laser wavelength squared. The attenuation induced by condensed metal vapors is the dominant attenuation mech- anism for a short wavelength laser, and it is described by the Rayleigh or Mie scattering theory (Refs. 57, 58). Under these, the attenuation coefficient $\beta$ is the sum of absorption coefficient $\beta_{a b s}$ and scattering coefficient $\beta_{s c a}$. The absorption coefficient $\beta_{a b s}$ and scattering coefficient $\beta_{\text {sca }}$ are given as follows (Refs. 58, 59):

$$
\begin{aligned}
& \beta_{a b s}=\frac{\pi^{2} d^{3} N_{P}}{\lambda} \operatorname{lm}\left(\frac{m^{2}-1}{m^{2}+2}\right) \\
& \beta_{s c a}=\frac{2 \pi^{5} d^{6} N_{P}}{3 \lambda^{4}} \operatorname{lm}\left(\frac{m^{2}-1}{m^{2}+2}\right)^{2}
\end{aligned}
$$

where $d$ is the particle diameter inside the vapor plume, $N_{P}$ is the particle density, $\lambda$ is the laser wavelength, and $m$ is the complex refractive index. According to the equation of state for ideal gas: $N_{P}=n_{P} / V_{P}=P_{A} / r T$, where $n_{P}$ is the number density of the particles, $V_{P}$ is the occupied volume by particles, $r$ is the gas constant, and $T$ is temperature. When $N_{P}$ is taken into Equations 17 and 18, the absorption coefficient $\beta_{a b s}$ and scattering coefficient $\beta_{a b s}$ are described as follows:

$$
\begin{gathered}
\beta_{a b s}=\frac{\pi^{2} d^{3} P_{A}}{\lambda r T} \operatorname{lm}\left(\frac{m^{2}-1}{m^{2}+2}\right) \\
\beta_{s c a}=\frac{2 \pi^{5} d^{6} P_{A}}{3 \lambda^{4} r T} \operatorname{lm}\left(\frac{m^{2}-1}{m^{2}+2}\right)^{2}
\end{gathered}
$$

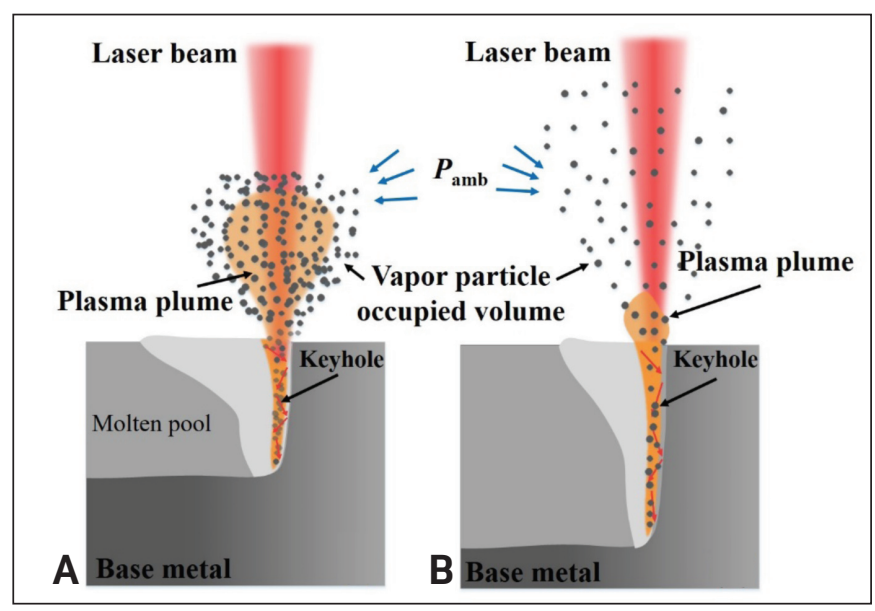

Fig. 8 - The schematic drawing of keyhole-mode laser welding: A - Atmospheric pressure; $B$ - reduced ambient pressure. 

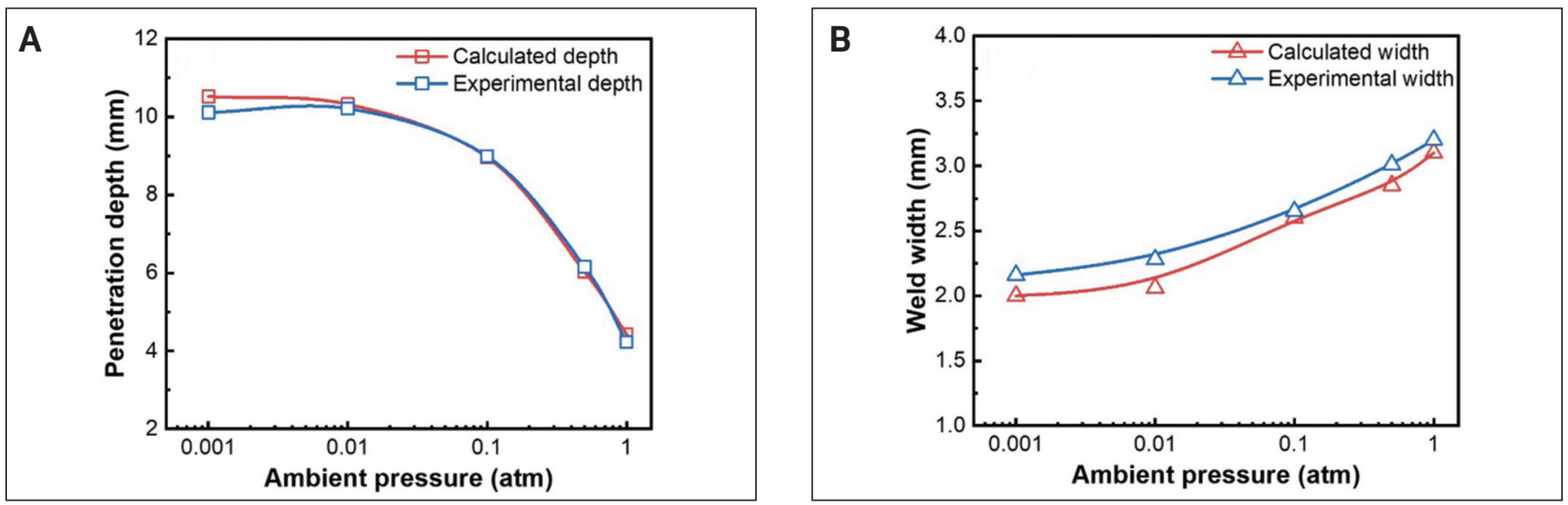

Fig. 9 - The experimental and corresponding calculations: A - Penetration depth; B - weld width for Structural Steel Q690 by considering both the variation in boiling point and plume attenuation coefficients for five ambient pressures.

According to Equations 19 and 20, the directly proportional relationship between the attenuation coefficient $\beta$ and ambient pressure $P_{A}$ was obtained while assuming the particle diameter and the ambient temperature were the same for the different ambient pressures. As shown schematically in Fig. 8B, the decrease of ambient pressure reduced the vapor particle density, lowering the value of the attenuation coefficient $\beta$. The value of $\beta$ was difficult to estimate because of the uncertainties in the values of the variables in the above equations. Mazumder and Steen used a value of $800 \mathrm{~m}^{-1}$ for welding of mild steel (Ref. 28). Kaplan provided a mean attenuation coefficient value of $100 \mathrm{~m}^{-1}$ for iron (Ref. 33). Rai et al. simulated keyhole mode laser welding of tantalum, Ti-6Al-4V, 304L stainless steel, and vana-

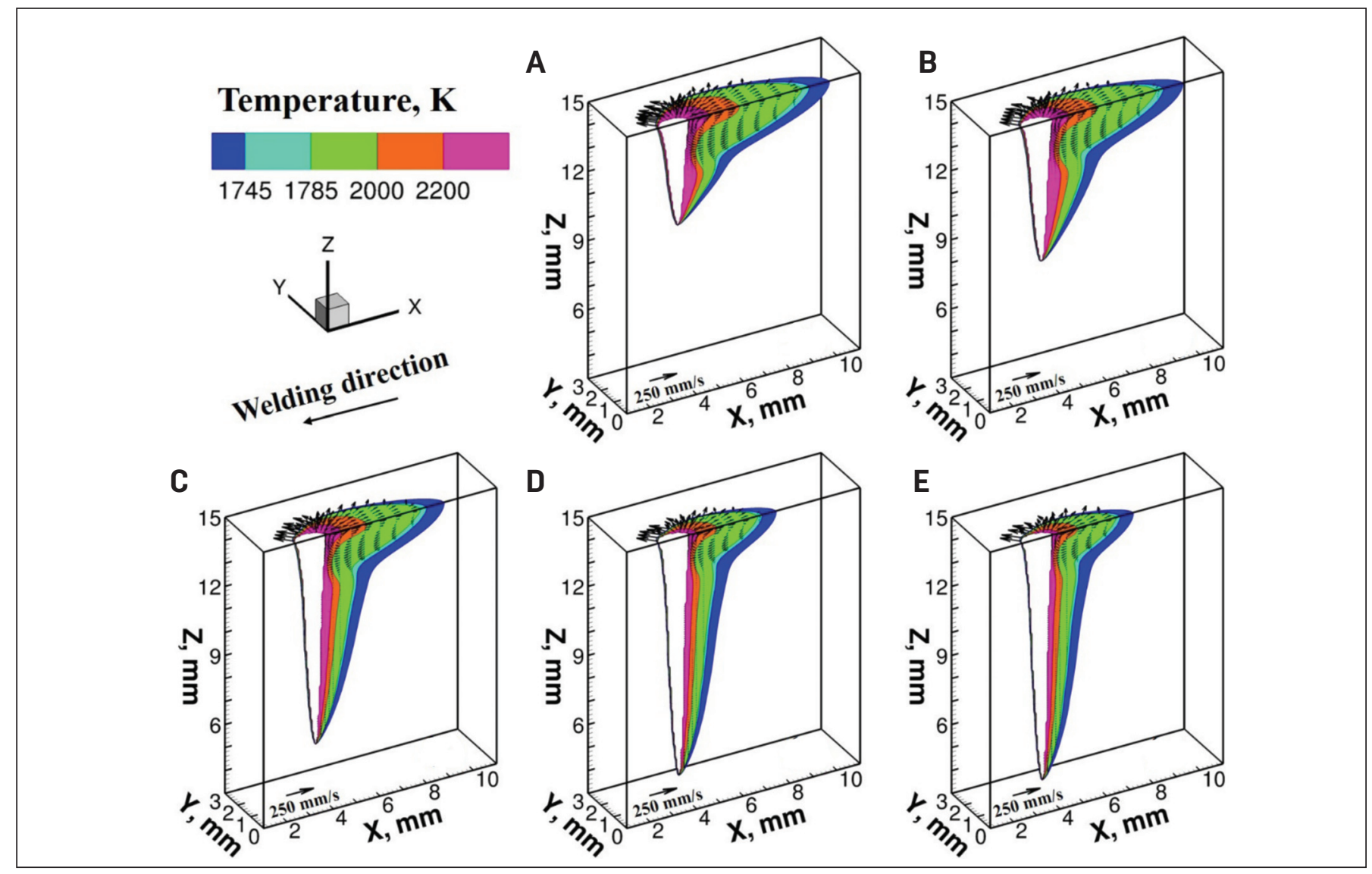

Fig. 10 - The calculated temperature and fluid flow field for laser welding of Structural Steel Q690 at five level ambient pressures: $A-1 \mathrm{~atm} ; B-0.5 \mathrm{~atm} ; C-0.1 \mathrm{~atm} ; D-0.01 \mathrm{~atm} ; E-0.001 \mathrm{~atm}$ by considering both the variation in boiling point and plume attenuation coefficient. 

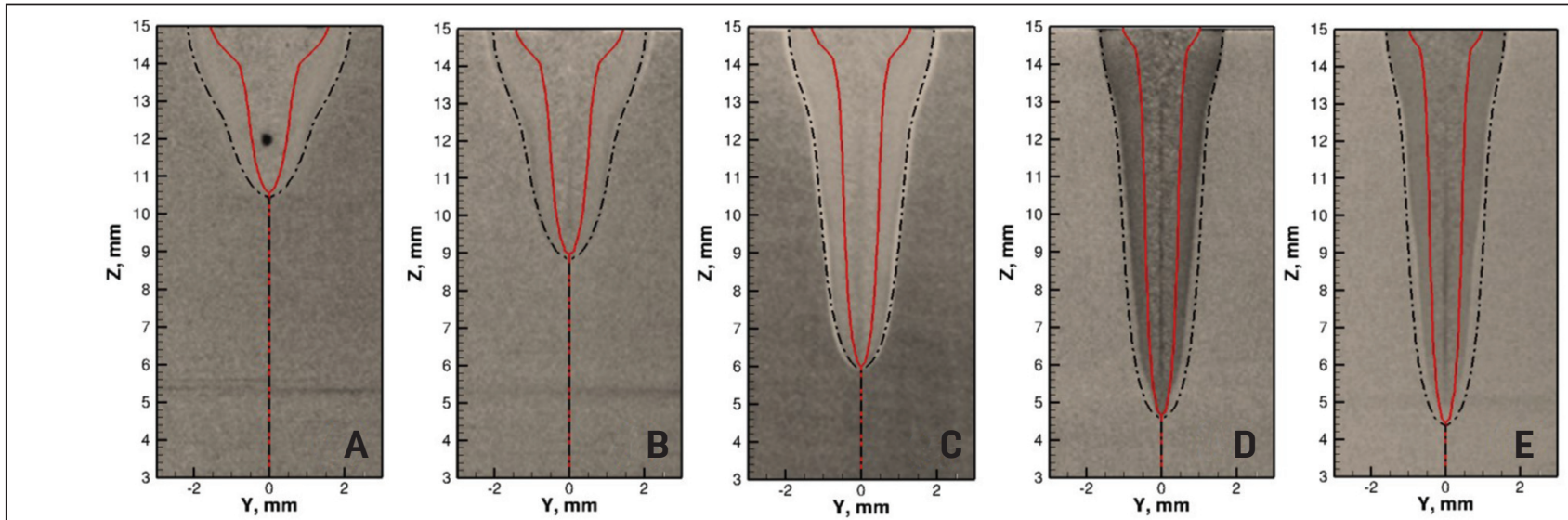

Fig. 11 - Comparison between the experimental and the calculated weld fusion cross sections of Structural Steel Q690 laser welds at various ambient pressures: $A-1 \mathrm{~atm} ; B-0.5 \mathrm{~atm} ; C-0.1 \mathrm{~atm} ; D-0.01 \mathrm{~atm} ; E-0.001$ atm by considering both the variation in boiling point and plume attenuation coefficient.

dium using the same attenuation coefficient value of 100 $\mathrm{m}^{-1}$ (Ref. 35). The literature values of the attenuation coefficient range from 800 to lower than $100 \mathrm{~m}^{-1}$, depending on the type of laser, power, speed of welding, material used, shielding gas, and other variables (Refs. 28, 35). Determining an exact value for a particular laser welding condition is a highly complex undertaking. However, there is a proportional relation between the attenuation coefficient and the total pressure for any given set of welding parameters, as observed from Equations 19 and 20. To consider the laser energy attenuation caused by metal vapors/plasma, the average attenuation coefficient used in this model is determined by achieving a good agreement of calculated and experimental fusion zone geometries at atmospheric pressure. The values of the attenuation coefficients $\beta$ for various materials at atmospheric pressure used in this work are listed in Table 1. The attenuation coefficients at lower pressures were obtained from the proportional relationship between plume attenuation coefficient and the ambient pressure.

Figure 9 shows the experimental and the corresponding calculated penetration depth and weld width for Structural Steel Q690, considering both the variation of the boiling point and laser beam attenuation for five ambient pressures. The calculated results of both the penetration depth and weld width showed good agreement with the corresponding experimental results. Figure 10 shows the calculated temperature and fluid flow field for Structural Steel Q690 welds made at various ambient pressure by considering both the variation of boiling point and plume attenuation coefficient. The keyhole depth increases with a decrease in ambient pressure. Comparing the temperature fields for various ambient pressures, the heat transfer was enhanced in the depth direction and was reduced in horizontal direction due to the decrease of beam attenuation and keyhole wall temperature. To illustrate the significance of the role of heat transfer by convection relative to heat transfer by conduction, the dimensionless Peclet number $(\mathrm{Pe})$ was calculated for ambient pressure of 1 and $0.001 \mathrm{~atm}$.

$$
P e=\rho u C_{p}(w / 2) / k
$$

where $\rho$ is the density, $u$ is the characteristic velocity, $C_{p}$ is the specific heat, $w$ is the weld pool width, and $k$ is the thermal conductivity. Considering a typical velocity of 100 $\mathrm{mm} / \mathrm{s}$, the properties of the liquid metal, and the calculated weld pool width, the Peclet number for 1 and 0.001 atm works out to be 41 and 13, respectively. Since the Peclet number is much greater than 1 , convection plays a significant role in the heat transfer process for both cases. In addition, the convective flow plays a more important role in the heat transfer at atmospheric pressure than that at reduced ambient pressures. The strong outward flow in the weld pool results in a relatively wide weld fusion zone at atmospheric pressure.

Figure 11 shows a comparison between the calculated and the experimental weld fusion cross sections of Structural Steel Q690 laser welds at various ambient pressures. A laser weld with deep penetration depth and narrow weld width characteristic of an electron beam weld was obtained at low ambient pressures. The calculated weld fusion cross sections agreed well with the corresponding experimental

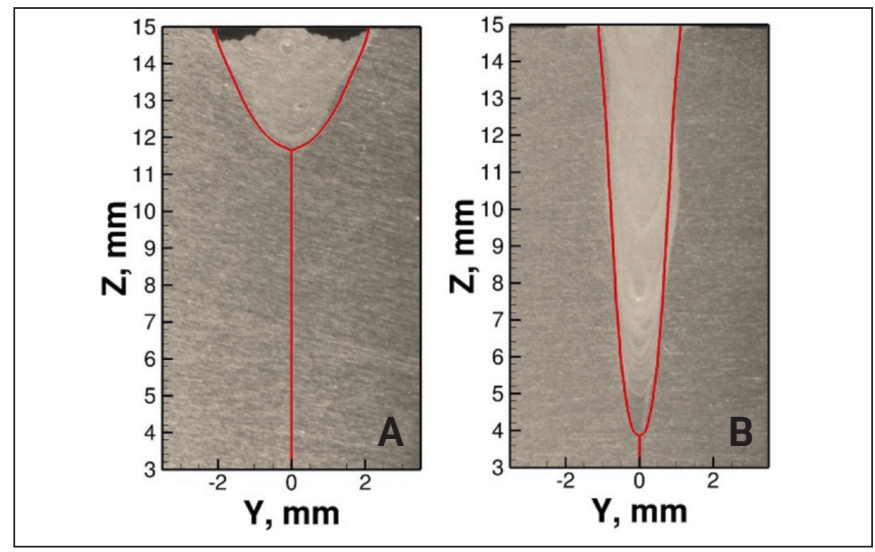

Fig. 12 - Comparison between the calculated weld fusion cross sections of Aluminum Alloy A5083 laser welds: A Atmospheric pressure (1 atm); $B$ - reduced ambient pressure (0.001 atm) with the corresponding experimental results. 


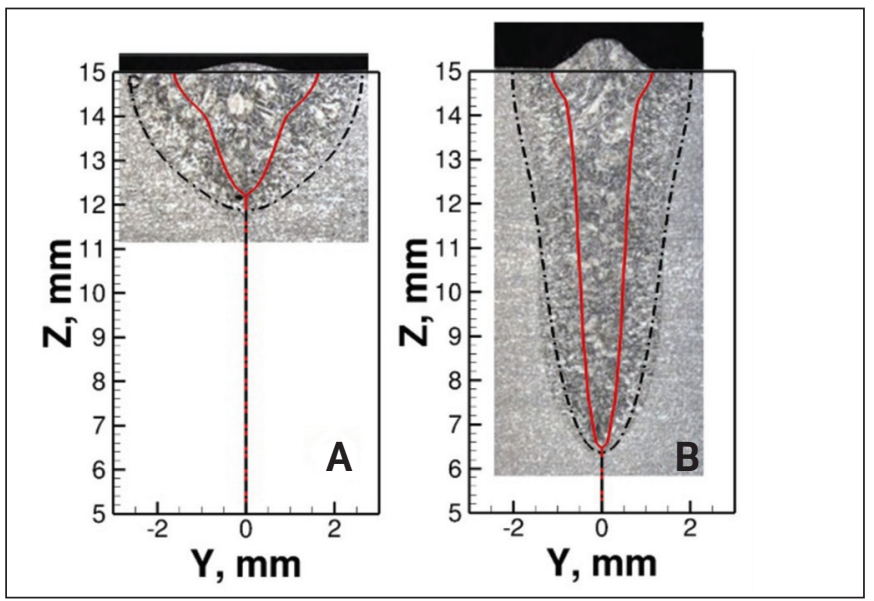

Fig. 13 - Comparison between the calculated weld fusion cross sections of pure titanium laser welds: A - Atmospheric pressure (1 atm); $B$ - reduced ambient pressure ( $0.1 \mathrm{mBar}$ ) with the corresponding experimental results of Elmer et al. (Ref. 16).

results for all ambient pressures.

To examine the effectiveness of the model to explain the role of reduced ambient pressure, experimental data for three other alloys that had very different thermophysical properties than the Q690 steel were compared with the model predictions. First, experimental data for the welding of Aluminum Alloy A5083 were compared with the corresponding model predictions. The results shown in Fig. 12 indicate good agreement between the calculated and experimental data. This agreement indicates promise that the model accurately represents the most important physical processes for keyhole-mode welding at various ambient pressures.

In addition to the data for Aluminum Alloy A5083, the independent experimental data of Elmer et al. (Ref. 16) for the welding of commercially pure titanium and Nickel 201 were also simulated. The commercially pure titanium was welded using 2075-W laser power and 17-mm/s welding speed, and the Nickel 201 was welded using 4150-W laser power and 12-mm/s welding speed. Figures 13 and 14 show a comparison between the experimental and the predicted results for commercially pure titanium and Nickel 201, respectively. The fair agreement between the calculated and the experimentally obtained fusion zone cross sections of commercially pure titanium and Nickel 201 welded at different ambient pressures indicates the validity of the physical processes considered in the simulations. The variation of the fusion zone geometry at various ambient pressures results from the effects of the depression of boiling point and changes in the plume attenuation coefficient.

\section{Summary and Conclusions}

The improvement of the depth of penetration during keyhole-mode welding of steel, aluminum alloy, commercially pure titanium, and Nickel 201 due to reduced ambient pressure was studied experimentally and theoretically. The investigation showed both the depression of the keyholewall temperature as well as the reduced absorption of the in-
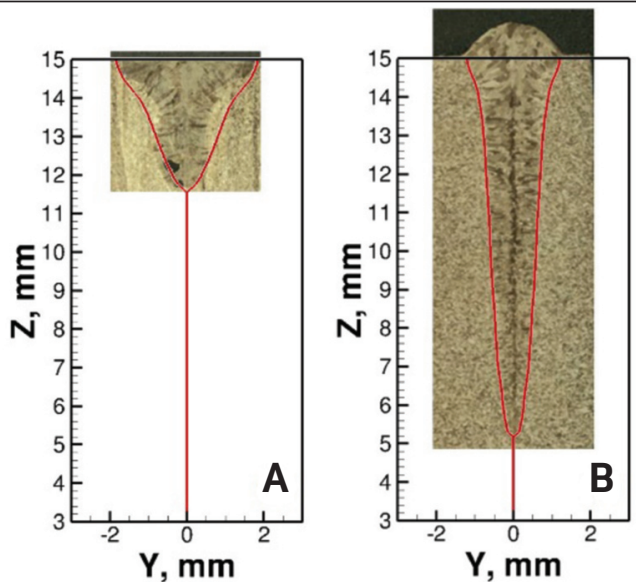

Fig. 14 - Comparison between the calculated weld fusion cross sections of Nickel 201 laser welds: A - Atmospheric pressure (1 atm); $B$ - reduced ambient pressure (0.1 mBar) with the corresponding experimental results of Elmer et al. (Ref. 16).

tensity of the laser beam by the plasma were responsible for the improved depth of penetration at lower ambient pressures. The following are the main findings.

1) The experimental results for the keyhole-mode welding of steel, aluminum alloy, commercially pure titanium, and Nickel 201 showed the weld geometry was sensitive to ambient pressure. The penetration depth increased and weld width decreased with the reduction of ambient pressure from 1 to $0.001 \mathrm{~atm}$.

2) The computed depths of penetration in a steel weld were considerably lower than the observed depths in a steel weld at low ambient pressures when the depression of the boiling point with a decrease in ambient pressure was considered. However, the experimental weld widths agreed well with the corresponding computed values.

3) The improvements in the depth of penetration could be accurately predicted for the keyhole-mode welding of steel, aluminum alloy, commercially pure titanium, and Nickel 201 when both the depression of the boiling point as well as the change in the vapor/plasma plume attenuation were considered.

4) The improvement in the depth of penetration at reduced ambient pressure was mainly due to the improved transmission of the laser beam through the vapor/plasma plume. Estimated values for laser attenuation coefficients are proposed for the four alloys studied.

5) The lower keyhole wall temperature and the reduced temperature gradient near the keyhole wall reduced the rate of heat transfer into the weld and resulted in narrower welds.

\section{Acknowledgments}

We acknowledge the interests of T. Mukherjee, J. S. Zuback, G. L. Knapp, Y. Du, and Q. R. Wu of Penn State University in this research. M. Jiang also acknowledges the support from the China Scholarship Council (Grant no. 201806120153). 


\section{References}

1. Reisgen, U., Olschok, S., and Longerich, S. 2010. Laser beam welding in vacuum - A process variation in comparison with electron beam welding. International Congress on Applications of Lasers \& Electro-Optics 2010: 638-647. DOI: 10.2351/1.5062093

2. Węglowski, M. S., Błacha, S., and Phillips, A. 2016. Electron beam welding - Techniques and trends - Review. Vacuum 130: 72-92. DOI: 10.1016/j.vacuum.2016.05.004

3. Steen, W. M., and Mazumder, J. 2010. Laser Material Processing. Springer London: London. DOI: 10.1007/978-1-84996-062-5

4. Kawahito, Y., Mizutani, M., and Katayama, S. 2009. High quality welding of stainless steel with $10 \mathrm{~kW}$ high power fibre laser. Science and Technology of Welding and Joining 14(4): 288-294. DOI: 10.1179/136217108X372531

5. Grupp, M., Klinker, K., and Cattaneo, S. 2013. Welding of high thicknesses using a fibre optic laser up to $30 \mathrm{~kW}$. Welding International 27(2): 109-112. DOI: 10.1080/09507116.2011.600043

6. Kawahito, Y., Wang, H., Katayama, S., and Sumimori, D.

2018. Ultra high power (100 kW) fiber laser welding of steel. Optics Letters 43(19): 4667. DOI: 10.1364/OL.43.004667

7. Blecher, J. J., Palmer, T. A., and DebRoy, T. 2015. Mitigation of root defect in laser and hybrid laser arc welding. Welding Journal 94(3): 73-s to 82-s.

8. Nakamura, H., Kawahito, Y., Nishimoto, K., and Katayama, S. 2015. Elucidation of melt flows and spatter formation mechanisms during high power laser welding of pure titanium. Journal of Laser Applications 27(3): 032012. DOI: 10.2351/1.4922383

9. Kaplan, A. F., and Powell, J. Spatter in laser welding. Journal of Laser Applications 23(3): 032005. DOI: 10.2351/1.3597830

10. Zhang, M., Chen, G., Zhou, Y., and Liao, S. 2014. Optimization of deep penetration laser welding of thick stainless steel with a $10 \mathrm{~kW}$ fiber laser. Materials and Design 53: 568-576.

DOI: 10.1016/j.matdes.2013.06.066

11. Shen, X., Li, L., Guo, W., Teng, W., and He, W. 2016. Comparison of processing window and porosity distribution in laser welding of $10 \mathrm{~mm}$ thick $30 \mathrm{CrMnSiA}$ ultrahigh strength between flat (1G) and horizontal (2G) positions. Journal of Laser Applications 28(2): 022418. DOI: 10.2351/1.4943992

12. Elmer, J. W., Vaja, J., Carlton, H. D., and Pong, R. 2015. The effect of $\mathrm{Ar}$ and $\mathrm{N}_{2}$ shielding gas on laser weld porosity in steel, stainless steel, and nickel. Welding Journal 94(10): 313-s to 325-s.

13. Jiang, Z., Tao, W., Yu, K., Tan, C., Chen, Y., Li, L., and Li, Z. 2016. Comparative study on fiber laser welding of GH3535 superalloy in continuous and pulsed waves. Materials and Design 110: 728-739. DOI: 10.1016/j.matdes.2016.08.055

14. Dittrich, D., Jahn, A., Standfuss, J., and Beyer, E. 2017. Laser beam welding of atmosphere aluminum die cast material using high frequency beam oscillation and brilliant beam sources. Journal of Laser Applications 29(2): 022425. DOI: 10.2351/1.4983250

15. Bachmann, M., Avilov, V., Gumenyuk, A., and Rethmeier, M. 2014. Experimental and numerical investigation of an electromagnetic weld pool support system for high power laser beam welding of austenitic stainless steel. Journal of Materials Processing Technology 214(3): 578-591. DOI: 10.1016/j.jmatprotec.2013.11.013

16. Elmer, J. W., Vaja, J., and Carlton, H. D. 2016. The effect of reduced pressure on laser keyhole weld porosity and weld geometry in commercially pure titanium and nickel. Welding Journal 95(11): 419-s to 430 -s.

17. Reisgen, U., Olschok, S., Jakobs, S., and Turner, C. 2016. Laser beam welding under vacuum of high grade materials. Welding in the World 60(3): 403-413. DOI: 10.1007/s40194-016-0302-3

18. Arata, Y., Abe, N., and Oda, T. 1985. Fundamental phenomena in high power $\mathrm{CO}_{2}$ laser (report II): Vacuum laser welding (welding physics, process \& instrument). Transactions of JWRI 14(2): 217-222.
19. Katayama, S., Kobayashi, Y., Mizutani, M., and Matsunawa, A. 2001. Effect of vacuum on penetration and defects in laser welding. Journal of Laser Applications 13(5): 187-192. DOI: 10.2351/ 1.1404413

20. Börner, C., Dilger, K., Rominger, V., Harrer, T., Krüssel, T., and Löwer, T. 2011. Influence of ambient pressure on spattering and weld seam quality in laser beam welding with the solid-state laser. International Congress on Applications of Lasers \& ElectroOptics 2011: 638-647. DOI: 10.2351/1.5062302

21. Jiang, M., Chen, X., Chen, Y., and Tao, W. 2019. Increasing keyhole stability of fiber laser welding under reduced ambient pressure. Journal of Materials Processing Technology 268: 213-222. DOI: 10.1016/j.jmatprotec.2019.01.026

22. Gao, M., Kawahito, Y., and Kajii, S. 2017. Observation and understanding in laser welding of pure titanium at subatmospheric pressure. Optics Express 25(12): 13539. DOI: 10.1364/OE.25. 013539

23. Jiang, M., Tao, W., Chen, Y., and Li, F. 2019. Comparison of processing window in full penetration laser welding of thick highstrength steel under atmosphere and sub-atmosphere. Optics \& Laser Technology 109: 449-455. DOI: 10.1016/j.optlastec.2018.08.023

24. Yang, S., Wang, J., Carlson, B. E., and Zhang, J. 2013. Vacuum-assisted laser welding of zinc-coated steels in a gap-free lap joint configuration. Welding Journal 92(7): 197-s to 204-s.

25. Youhei, A., Yousuke, K., Hiroshi, N., Koji, N., Masami, M., and Seiji, K. 2014. Effect of reduced pressure atmosphere on weld geometry in partial penetration laser welding of stainless steel and aluminium alloy with high power and high brightness laser. Science and Technology of Welding and Joining 19(4): 324-332. DOI:

10.1179/1362171813Y.0000000182

26. Jiang, M., Tao, W., Wang, S., Li, L., and Chen, Y. 2017. Effect of ambient pressure on interaction between laser radiation and plasma plume in fiber laser welding. Vacuum 138: 70-79. DOI: 10.1016/j.vacuum.2017.01.012

27. Swift-Hook, D. T., and Gick, A. E. F. 1973. Penetration welding with lasers. Welding Journal 52(11): 492-s to 499-s.

28. Mazumder, J., and Steen, W. M. 1980. Heat transfer model for CW laser material processing. Journal of Applied Physics 51(2): 941-947. DOI: 10.1063/1.327672

29. Tan, W., Bailey, N. S., and Shin, Y. C. 2013. Investigation of keyhole plume and molten pool based on a three-dimensional dynamic model with sharp interface formulation. Journal of Physics D: Applied Physics 46(5): 055501. DOI: 10.1088/0022-3727/46/5/055501

30. Huang, B., Chen, X., Pang, S., and Hu, R. 2017. A threedimensional model of coupling dynamics of keyhole and weld pool during electron beam welding. International Journal of Heat and Mass Transfer 115: 159-173. DOI: 10.1016/j.ijheatmasstransfer. 2017.08.010

31. Chen, G., Liu, J., Shu, X., Gu, H., and Zhang, B. 2019. Numerical simulation of keyhole morphology and molten pool flow behavior in aluminum alloy electron-beam welding. International Journal of Heat and Mass Transfer 138: 879-888. DOI: 10.1016/ j.ijheatmasstransfer.2019.04.112

32. Dowden, J., Postacioglu, N., Davis, M., and Kapadia, P. 1987. A keyhole model in penetration welding with a laser. Journal of Physics D: Applied Physics 20(1): 36-44. DOI: 10.1088/0022-3727/ 20/1/006

33. Kaplan, A. 1994. A model of deep penetration laser welding based on calculation of the keyhole profile. Journal of Physics D: Applied Physics 27(9): 1805-1814. DOI: 10.1088/0022-3727/27/9/002

34. Ki, H., Mazumder, J., and Mohanty, P. S. 2002. Modeling of laser keyhole welding: Part I. Mathematical modeling, numerical methodology, role of recoil pressure, multiple reflections, and free surface evolution. Metallurgical and Materials Transactions A 33(6): 1817-1830. DOI: 10.1007/s11661-002-0190-6

35. Rai, R., Elmer, J. W., Palmer, T. A., and DebRoy, T. 2007. Heat transfer and fluid flow during keyhole mode laser welding of 
tantalum, Ti-6Al-4V, 304L stainless steel and vanadium. Journal of Physics D: Applied Physics 40(18): 5753-5766. DOI: 10.1088/00223727/40/18/037

36. Cho, J. H., and Na, S. J. 2009. Three-dimensional analysis of molten pool in GMA-laser hybrid welding. Welding Journal 88(2):

35 -s to 44 -s.

37. Geiger, M., Leitz, K.-H., Koch, H., and Otto, A. 2009. A 3D transient model of keyhole and melt pool dynamics in laser beam welding applied to the joining of zinc coated sheets. Production Engineering 3(2): 127-136. DOI: 10.1007/s11740-008-0148-7

38. Pang, S., Chen, L., Zhou, J., Yin, Y., and Chen, T. 2011. A three-dimensional sharp interface model for self-consistent keyhole and weld pool dynamics in deep penetration laser welding. Journal of Physics D: Applied Physics 44(2): 025301. DOI: 10.1088/ 0022-3727/44/2/025301

39. Rai, R., Roy, G. G., and DebRoy, T. 2007. A computationally efficient model of convective heat transfer and solidification characteristics during keyhole mode laser welding. Journal of Applied Physics 101(5), Article Number: 054909. DOI: 10.1063/1.2537587

40. Ribic, B., Rai, R., and DebRoy, T. 2008. Numerical simulation of heat transfer and fluid flow in GTA/laser hybrid welding. Science and Technology of Welding and Joining 13(8): 683-693. DOI: 10.1179/136217108X356782

41. Rai, R., Kelly, S. M., Martukanitz, R. P., and DebRoy, T. 2008. A convective heat-transfer model for partial and full penetration keyhole mode laser welding of a structural steel. Metallurgical and Materials Transactions A: Physical Metallurgy and Materials Science 39(1): 98-112. DOI: 10.1007/s11661-007-9400-6

42. Rai, R., Burgardt, P., Milewski, J. O., Lienert, T. J., and DebRoy, T. 2009. Heat transfer and fluid flow during electron beam welding of $21 \mathrm{Cr}-6 \mathrm{Ni}-9 \mathrm{Mn}$ steel and $\mathrm{Ti}-6 \mathrm{Al}-4 \mathrm{~V}$ alloy. Journal of Physics D: Applied Physics 42(2): 025503. DOI: 10.1088/00223727/42/2/025503

43. Rai, R., Palmer, T. A., Elmer, J., and DebRoy, T. 2009. Heat transfer and fluid flow during electron beam welding of 304L stainless steel alloy. Welding Journal 88(3): 54-s to 61-s.

44. Liu, T., Yang, L. J., Wei, H. L., Qiu, W. C., and DebRoy, T. 2017. Composition change of stainless steels during keyhole mode laser welding. Welding Journal 96(7): 258-s to 170-s.

45. Patankar, S. V. 1980. Numerical Heat Transfer and Fluid Flow. Hemisphere Publishing Corp., New York, N.Y. DOI: 10.1201/ 9781482234213

46. Voller, V. R., and Prakash, C. 1987. A fixed grid numerical modelling methodology for convection-diffusion mushy region phase change problems. International Journal of Heat and Mass Transfer 30: 1709-1720. DOI: 10.1016/0017-9310(87)90317-6

47. Mishra, S., and DebRoy, T. 2005. A heat-transfer and fluidflow-based model to obtain a specific weld geometry using various combinations of welding variables. Journal of Applied Physics 98(4): 044902. DOI: 10.1063/1.2001153

48. He, X., DebRoy, T., and Fuerschbach, P. W. 2003. Probing temperature during laser spot welding from vapor composition and modeling. Journal of Applied Physics 94(10): 6949-6958.

DOI: $10.1063 / 1.1622118$

49. De, A., and DebRoy, T. 2004. Probing unknown welding parameters from convective heat transfer calculation and multivariable optimization. Journal of Physics D: Applied Physics 37(1): 140. DOI: 10.1088/0022-3727/37/1/023

50. Yaws, C. L. 1994. Handbook of Vapor Pressure. Houston, Tex., Gulf Publishing Co.

51. Collur, M. M., and DebRoy, T. 1989. Emission spectroscopy of plasma during laser welding of AISI 201 stainless steel. Metallur gical and Materials Transactions B 20(2): 277-286. DOI: 10.1007/ BF02825608

52. Griem, H. R. 1964. Plasma Spectroscopy. McGraw-Hill, New York, N.Y. DOI: 10.1119/1.1971040

53. Boumans, P. W. 1966. Theory of Spectrochemical Excitation.
Hilger and Watts Ltd., London. DOI: 10.1007/978-1-4684-8428-1

54. Dunn, G. J., Allemand, C. D., and Eagar, T. W. 1986. Metal vapors in gas tungsten arcs: Part I. Spectroscopy and monochromatic photography. Metallurgical and Materials Transactions A 17(10): 1851-1863. DOI: 10.1007/BF02817281

55. Dunn, G. J., and Eagar, T. W. 1986. Metal vapors in gas tungsten arcs: Part II. Theoretical calculations of transport properties. Metallurgical and Materials Transactions A 17(10): 1865-1871. DOI: 10.1007/BF02817282

56. Kawahito, Y., Matsumoto, N., Mizutani, M., and Katayama, S. 2008. Characterisation of plasma induced during high power fibre laser welding of stainless steel. Science and Technology of Welding and Joining 13(8): 744-748. DOI: 10.1179/136217108X329313

57. Shcheglov, P. Y., Uspenskiy, S. A., Gumenyuk, A. V., Petrovskiy, V. N., Rethmeier, M., and Yermachenko, V. M. 2011. Plume attenuation of laser radiation during high power fiber laser welding. Laser Physics Letters 8(6): 475-480. DOI: 10.1002/lapl.201110010

58. Greses, J., Hilton, P. A., Barlow, C. Y., and Steen, W. M. 2006. Plume attenuation under high power $\mathrm{Nd}$ :yttritium-aluminumgarnet laser welding. Journal of Laser Applications 16(1): 9-15. DOI: $10.2351 / 1.1642636$

59. Park, K. W., and Na, S. J. 2010. Theoretical investigations on multiple-reflection and Rayleigh absorption-emission-scattering effects in laser drilling. Applied Surface Science 256(8): 2392-2399. DOI: 10.1016/j.apsusc.2009.10.073

60. Collur, M. M., Paul, A., and DeRoy, T. 1987. Mechanism of alloying element vaporization during laser-welding. Metallurgical Transactions B 18(4): 733-740. DOI: 10.1007/BF02672891

\section{Appendix A}

\section{Calculation of Keyhole Geometry}

The laser energy is absorbed on the keyhole wall and transferred into the molten metal. The local angle of the keyhole wall is determined by the balance between heat flux transferred into the keyhole wall, the locally absorbed beam energy flux, and the heat loss due to heat of evaporation. The local keyhole wall angle with the vertical direction is given by the following (Ref. 33):

$$
\tan (\theta)=\frac{I_{c}}{I_{a}-I_{v}}
$$

where $I_{c}$ is the radial heat flux conducted into the keyhole wall, $I_{a}$ is the locally absorbed beam energy, and $I_{v}$ is the evaporative heat flux on the keyhole wall.

The value of $I_{c}$ is obtained from a two-dimensional temperature field in an infinite plate with reference to a linear heat source as follows (Ref. 33):

$$
I_{c}(r, \varphi)=-\lambda \frac{\partial T(r, \varphi)}{\partial r}
$$

where $T(r, \varphi)$ indicates a location in the plate with the line source as the origin, $T$ is the temperature, and $\lambda$ is the thermal conductivity. The two-dimensional temperature field, $T(r, \varphi)$, can be calculated conduction heat from the keyhole wall into the plate as follows (Ref. 33): 


$$
T(r, \varphi)=T_{a}+\frac{P^{\prime}}{2 \pi \lambda} K_{0}(\Omega r) e^{-\Omega \cos \varphi}
$$

where $T_{a}$ is the ambient temperature, $P^{\prime}$ is the power per unit depth, $K_{0}()$ is the zero-order second kind modified Bessel function, and $\Omega=v /(2 \kappa)$, where $v$ is the welding speed and $\kappa$ is the thermal diffusivity.

The locally absorbed beam energy flux, $I_{a}$, on the keyhole wall is obtained by considering the Fresnel absorption during multiple reflections and the metal vapors/plasma absorption as follows (Ref. 33):

$$
I_{a}=e^{-\beta L}\left(1-(1-\alpha)^{1+\pi / 4 \bar{\theta}}\right) I_{0}
$$

where $\beta$ is the plume attenuation coefficient, $L$ is the average path of the laser beam in metal vapors/plasma before it reaches the keyhole wall, $\alpha$ is the absorption coefficient of the workpiece, $\bar{\theta}$ is the average angle between the keyhole wall and the initial incident beam axis, and $I_{0}$ is the local beam intensity, which varies with depth from the surface and radial distance from the beam axis, and is given by the following (Ref. 33):

$$
I_{0}=I_{p}\left(\frac{r_{0}}{r_{f}}\right)^{2} \exp \left(=\frac{r^{2}}{r_{f}^{2}}\right)
$$

where $I_{p}$ is the peak intensity at the focal point, given by $2 P /\left(\pi r_{0}^{2}\right), P$ is the laser power, $r_{0}$ is the beam radius at the focal point, and $r_{f}$ is the local beam radius, which is calculated by the following (Ref. 33):

$$
r_{f}=r_{0}\left(1+\left(\frac{z+z_{0}}{2 r_{0} l / d_{b}}\right)^{2}\right)^{1 / 2}
$$

where $z$ and $z_{0}$ are the depth and the beam defocusing, respectively. $l$ is the beam focal length, and $d_{b}$ is the beam diameter on the laser focusing lens.

The vaporization flux, $I_{v}$, on the keyhole wall is given by the following (Ref. 33):

$$
I_{v}=\sum_{i=1}^{n} J_{i} \Delta H_{i}
$$

where $J_{i}$ is the vaporization flux of element $i, \Delta H_{i}$ is the heat of vaporization of element $i$, and $n$ is the total number of alloying elements in the alloy. For simplicity, the vaporization flux of element $i$ was calculated by using the Langmuir equation as follows (Ref. 60):

$$
J_{i}=\frac{P_{i}}{7.5} \sqrt{\frac{M_{i}}{2 \pi R T_{b}}}
$$

where $P_{i}$ is the vapor pressure of element $i$ over the alloy, $M_{i}$ is the molecular weight of element $i, T_{b}$ indicates the boiling temperature of the alloy, and $R$ is the gas constant.

\section{Welding Journal Now Publishing Direct Object Identifier (DOI) Numbers}

Dear members of the welding research community,

Note that in each issue of the Welding Journal Research Supplement, we are including Direct Object Identifier (DOI) numbers with each of the papers published in print and online. A direct object identifier is a unique alphanumeric string assigned by a registration agency (we are using Crossref.org) to identify content and provide a persistent link to its location on the Internet. Our decision to begin assigning a DOI for each paper comes directly from a request by the research community.
As part of our obligation to Crossref.org, we are asked to provide DOI numbers, when available, in the references section of papers. So, if you have submitted a paper to the Welding Journal or are planning on submitting a paper, we ask that you update your references to include DOI numbers whenever possible.

Thank you.

Annette Alonso,

Publisher, Welding Journal 